\title{
GESTÃo AMBIENTAL: PRODUÇÃO CIENTÍFICA DIVULGADA EM PERIÓDICOS NACIONAIS QUALIS B1 a B4 - CAPES
}

\author{
Alexandre Costa Quintana \\ Mestre em Administração pela Universidade Federal de Santa Catarina - UFSC \\ Professora do Instituto de Ciências Econômicas, Administrativas e Contábeis da Universidade Federal \\ do Rio Grande - FURG \\ quintana@vetorial.net (Brasil)
}

\section{Débora Gomes Machado}

Doutora em Ciências Contábeis e Administração pela Universidade Regional de Blumenau - FURB Professora do Instituto de Ciências Econômicas, Administrativas e Contábeis da Universidade Federal do Rio Grande - FURG

debora_furg@yahoo.com.br (Brasil)

\section{Cybele Troina do Amaral}

Mestre em Ciências Contábeis pela Universidade do Vale do Rio dos Sinos - UNISINOS cyta@ig.com.br (Brasil)

\section{Cristiane Gularte Quintana}

Mestre em Administração pela Universidade de Caxias do Sul - UCS

Professora do Instituto Federal de Educação, Ciência e Tecnologia do Rio Grande do Sul - IFRS cristianequintana@ hotmail.com (Brasil)

\section{RESUMO}

A preocupação com o meio ambiente data do século XIX, mas somente em 1972, com a Conferência Mundial sobre o Meio Ambiente, realizada em Estocolmo, que os países e a sociedade como um todo começaram, de forma mais efetiva, a se preocupar com a questão ambiental a nível mundial. Nesse contexto, surge a seguinte questão de pesquisa: como a gestão ambiental está sendo explorada na literatura científica permanente de Administração e Contabilidade? O objetivo geral deste trabalho é identificar como a gestão ambiental está sendo explorada na literatura científica permanente, de Administração e Contabilidade, em periódicos classificados nos níveis Webqualis B1 a B4 pela CAPES. A pesquisa classifica-se como básica e exploratória. Também, se enquadra como pesquisa descritiva e pesquisa bibliométrica. Quanto à abordagem do problema a pesquisa classifica-se como quantitativa e a coleta de dados foi documental. Os resultados foram no sentido de concluir, que a quantidade de estudos em Gestão Ambiental, nos periódicos pesquisados, é bastante limitada, focando a pesquisa bibliográfica, realizada por meio documental, que não exploram a realidade da Gestão Ambiental com a devida profundidade, detendo-se, apenas na evolução do desempenho ambiental e na informação gerada sobre as questões ambientais, sem destacar os reflexos que um processo de gestão ambiental pode trazer para a gestão das entidades e para a sociedade em geral.

Palavras chave: Gestão Ambiental; Pesquisa Bibliométrica; Produção Científica. 


\section{INTRODUÇÃ̃O}

A preocupação com o meio ambiente, já é tema de discussão desde o século XIX, mas somente em 1972, com a Conferência Mundial sobre o Meio Ambiente, realizada em Estocolmo, que os países e a sociedade como um todo começaram, de forma mais efetiva, a se preocupar com a questão ambiental a nível mundial.

Na década de 90, logo após a Conferência das Nações Unidas para o Meio Ambiente e o Desenvolvimento, mais conhecida como ECO-92, essa preocupação tornou-se um compromisso, com a produção de um documento chamado Agenda 21. Essa preocupação/compromisso surgiu em todas as áreas. Ferreira (2009, p.14) pontua que "a Agenda 21 trata da necessidade de que países e organismos internacionais desenvolvam um sistema de contabilidade que integre as questões sociais, ambientais e econômicas." Desta forma fica explícita a relação direta da contabilidade, de âmbito ambiental, com as empresas.

Considerando a relevância dos temas abordados, crescem os estudos relacionados a analisar a produção científica desenvolvida em periódicos, gerando estudos bibliométricos. Pode-se citar pesquisas elaboradas por Theóphilo (2004); Beuren, Schlindwein e Pasqual (2007); Espejo, Cruz, Lourenço e Antonovz (2008); Diehl e Souza (2008); Barbosa, Machado e Quintana (2011). Os autores procuraram descrever os trabalhos publicados ou apresentados em periódicos e eventos científicos, respectivamente, colaborando para apresentar um mapa dos estudos em contabilidade.

Gallon, Souza, Rover e Van Bellen (2007), de forma mais específica, realizaram um estudo sobre a produção científica e perspectivas teóricas da área ambiental, por meio de um levantamento em artigos publicados em congressos e periódicos da área de contabilidade e administração, entre 2000 e 2006, evidenciaram que na análise de 186 artigos encontrados, há similaridade entre os artigos publicados no Congresso USP de Controladoria e Contabilidade e no Encontro Anual da Associação Nacional de Pós-Graduação e Pesquisa em Administração - EnANPAD, no que diz respeito ao tipo de estudo, abordagem metodológica e quantidade de autores por artigo, e que os artigos das Revistas apresentam características próprias. Quanto às categorias identificadas na pesquisa, os autores concluíram que há estreita conformidade entre os temas gestão ambiental e evidenciação contábil, que embora a gestão ambiental apresente características mais próximas destes temas do que a da sustentabilidade, esta não se faz de forma tão evidente.

Nesse contexto, surge a seguinte questão de pesquisa: como a gestão ambiental está sendo explorada na literatura científica permanente de Administração e Contabilidade? O objetivo geral deste trabalho é identificar como a gestão ambiental está sendo explorada na literatura científica permanente,

Revista de Administração e Inovação, São Paulo, v. 11, n.2, p. 07-29, abr./jun. 2014. 
de Administração e Contabilidade, em periódicos classificados nos níveis Webqualis B1 a B4 pela Coordenação de Aperfeiçoamento de Pessoal de Nível Superior [CAPES] (2011).

Os objetivos específicos que contribuem para o alcance do objetivo geral são: a) identificar quais os temas que são tratados nas publicações; b) verificar a quantidade de autores por artigo; c) identificar os autores entre os artigos encontrados, que mais publicaram sobre o assunto; d) identificar a metodologia utilizada nas pesquisas; e e) verificar as referências utilizadas nos estudos.

Esse estudo se torna relevante, à medida que busca difundir o assunto, de cunho ambiental, pois a literatura permanente brasileira, acerca do mesmo pode ser considerada embrionária, diante de tantos problemas ambientais mundiais existentes, tais como o vazamento de óleo no golfo do México e nos Estados Unidos da América do Norte. "Um programa de financiamentos estaduais foi ativado na segunda-feira na Flórida que permite que pequenas empresas do Golfo financiem até US\$25.000 para compensar as perdas provocadas pelo vazamento.” Essa informação veiculada no Portal Eco Debate: Cidadania e Meio Ambiente mostra a vinculação entre meio ambiente e gestão, pois, afinal, se houveram perdas, as mesmas devem ser registradas. Tal desastre ambiental necessita de reflexão teórico-empírica acerca dessa temática, tão relevante para a continuidade da vida e dos ecossistemas.

\section{REVISÃO DE LITERATURA}

Esta seção trata dos temas acerca da gestão ambiental que subsidiam o estudo em questão.

Conforme Kitzmann (2009) a gestão ambiental é uma importante estratégia de transição; não afetará o rumo da sociedade sozinha, apenas pode garantir mais tempo e melhor qualidade de vida para que sejam criadas as condições adequadas. A autora complementa que a implementação da gestão ambiental tem ligação direta com as iniciativas de Educação Ambiental, tanto por entidades privadas como públicas.

\subsection{Gestão Ambiental}

Em 31 de agosto de 1981, através da Lei no 6.938 no Brasil, estabeleceram-se os objetivos e instrumentos da Política Nacional de Meio Ambiente (PNMA), sendo essa considerada o comprometimento de conciliação do desenvolvimento econômico com a preservação ambiental, a partir dessa lei criou-se o Sistema Nacional de Meio Ambiente, formado por um órgão colegiado: o Conselho Nacional do Meio Ambiente - CONAMA. A partir de 1988, destacam-se alguns acontecimentos relevantes: a inclusão dos princípios ambientais na Constituição, no seu capítulo VI,

Revista de Administração e Inovação, São Paulo, v. 11, n.2, p. 07-29, abr./jun. 2014. 
artigo 225; a aprovação da Lei de Crimes Ambientais no Brasil, e a punição civil, administrativa e criminal das condutas e atividades consideradas lesivas ao meio ambiente. Essa lei veio como um instrumento de garantia para os órgãos ambientais e Ministério Público, agirem com eficácia na punição dos infratores das questões relacionadas com o meio ambiente (Almeida, 2010).

A gestão ambiental está composta por um conjunto das atividades administrativas e operacionais, que envolvem planejamento, direção, controle, alocação de recursos e outras realizadas, com o objetivo de obter efeitos positivos sobre o meio ambiente, procurando reduzir ou eliminar os danos causados pelas ações humanas. O processo de gestão ambiental é a forma pela qual a organização se mobiliza, interna e externamente para a conquista da qualidade ambiental desejada (Kraemer, 2002; Barbieri, 2007).

Também, em relação a gestão ambiental, deve-se ressaltar que envolve medidas e procedimentos, que permitam reduzir e controlar os impactos proporcionados por empreendimentos sobre o meio ambiente, e para que realmente, aconteça e se realize a gestão ambiental, é preciso que a potencialidade se transforme em ação concreta, traduzindo-se em problemas resolvidos (Philippi, 2002; Rosseti, 2008).

Conforme Oliveira (2009, p.25), “apesar do custo de inserir inovação e projeto para recuperação de recursos naturais, a gestão ambiental proporciona vantagens para a organização com relação aos benefícios econômicos e estratégicos incorporados em seu planejamento". As questões referentes ao termo ambiental interferem na tomada de decisão, cabe ao administrador analisar as causas e as consequências em não acatar os requisitos da responsabilidade ambiental, em função das influências realizadas pela sociedade e a política ambiental.

Ferreira (2009) complementa que a razão principal da existência da gestão ambiental é que ela deve propiciar o melhor retorno econômico possível sobre os recursos da entidade, considerando a preservação do meio ambiente.

Um caminho de implementação da gestão ambiental denomina-se educação ambiental. Segundo Moraes (2006), a educação ambiental é estudada e definida por diversos estudiosos que destacam os seus pontos de vista individuais e/ou profissionais, mas todas as abordagens enfatizam o seu caráter interdisciplinar, envolvendo diversas áreas técnico-científicas ligadas à questões sociais, culturais e do meio ambiente. Assim, destacando a relação entre a gestão ambiental e as questões sociais.

Conforme Nascimento, Lemos e Mello (2008), a gestão ambiental e a gestão social até o final do século XX eram percebidas pelas empresas como um passivo necessário para atender os ditames legais. Neste período, iniciou-se um movimento internacional de responsabilidade social, que passou a 
ter mais visibilidade e consideração, surgindo uma organização norte-americana denominada Business for Social Responsability (BSR). Neste sentido, a responsabilidade social ou socioambiental começa a despontar como elemento fundamental na gestão ambiental.

\subsection{Responsabilidade Socioambiental}

O objetivo final da responsabilidade social é o desenvolvimento sustentável, essa perspectiva pode ser percebida, considerando que para desempenhar sua atividade fim, a empresa obtém recursos necessários à produção, que tem origem no meio ambiente, recursos humanos e financeiros, provenientes da sociedade e, por consequência, é seu papel restabelecer essas fontes de recursos sob a forma de ações sociais. Desta forma, no ambiente empresarial as questões ambientais estão inseridas no conceito de responsabilidade social, como uma forma de evidenciar que a educação ambiental não se trata de uma ação isolada, mas deve estar inserida na cultura organizacional (Bianchi, Gelatti, Lelis \& Lobato, 2010).

O foco da responsabilidade social na empresa está relacionado a promoção da atuação organizacional ética, surgindo da necessidade de mostrar ao empresário a relevância de seu papel na promoção da qualidade de vida da comunidade que o cerca (Nascimento et al., 2008).

De acordo com Sirvinskas (2010), a ética ambiental relaciona-se a compreensão que o homem tem sobre a necessidade de preservar ou conservar os recursos naturais essenciais à perpetuação de todas as espécies de vida existentes no planeta, isto tudo está relacionado com a alteração nas condições físicas, químicas e biológicas do meio ambiente, ocasionada pelas atividades empresariais.

Neste sentido, surgem instrumentos para normatizar o reflexo da atuação do homem no meio ambiente, como a norma ISO 14001, aceita mundialmente para certificação dos Sistemas de Gestão Ambiental (SGAs). Apesar de sua adoção não resultar em garantir que os problemas de natureza ambiental de uma empresa estejam resolvidos, a ISO 14000 e subséries, estabelecem as diretrizes básicas para a implementação de um SGA, constituindo-se em um processo estruturado, genérico e completo, com o objetivo de melhoria contínua do desempenho em relação ao meio ambiente (Alberton \& Costa, 2007).

O sistema de gestão ambiental requer um processo de transformação no qual a exploração dos recursos e a orientação dos investimentos reforçam o ambiente de forma a manter e, se possível, ampliar seu potencial para atender às necessidades humanas. (Lacombe \& Heilborn, 2008)

No que diz respeito a gastos e investimentos no meio ambiente, estes devem ser evidenciados, conforme descrito por Paiva (2009):

Revista de Administração e Inovação, São Paulo, v. 11, n.2, p. 07-29, abr./jun. 2014. 
a) todos os gastos e as provisões efetuados com o meio ambiente devem ser evidenciados, bem como todas as situações relacionadas diretamente com a natureza que possam vir a prejudicar os interesses dos acionistas minoritários ou representem algum tipo de risco para a continuidade da empresa e da sociedade. Classificam-se em gastos voluntários e gastos involuntários.

b) o processo de inserção no ambiente mundial torna indispensável o atendimento de requisitos ambientais, sendo a evidenciação a forma de torná-los públicos. O caráter global de grande parte das empresas exige que essas devam deixar transparecer um grau de preocupação e de amadurecimento elevados, demonstrando a existência de uma consciência ambiental desenvolvida.

c) no momento em que haja a percepção do fato gerador, as atitudes da empresa devem-se materializar no sentido de interação com o meio ambiente, neste momento as ações devem ser postas em prática proporcionando a defesa, conservação e recuperação do mesmo. A postura antecipadora e de caráter preventivo passa a ser delineada, e toda e qualquer ação por parte da empresa deve ser revelada aos clientes atuais e potenciais, assim como aos fornecedores e outros usuários das informações contábeis.

d) a forma de evidenciar deve ser a mais prática possível, utilizando os instrumentos já existentes. Havendo a disposição de tornar pública, e por consequência fazendo com que as empresas os divulguem em vários veículos de comunicação e de diversas formas, que não permitem o estabelecimento de parâmetros para completo entendimento, comparação e julgamento. Na atualidade, as formas de evidenciação de fatos ou transações ambientais são as tradicionalmente utilizadas, compostas pelo relatório da administração e notas explicativas, e as formas alternativas, ainda incipientes, encontradas em páginas da Internet e divulgações esporádicas em revistas de grande circulação.

Para Almeida (2010) é fundamental para as empresas divulgar suas ações de forma transparente, inclusive o que se refere a passivos sociais e ambientais, que devem ser evidenciados, fazendo parte da estratégia de negócios, que ainda envolve a visão e a prática dos códigos e normas que servem como indicadores de sustentabilidade.

Portanto, conforme Nascimento et al. (2008), a Responsabilidade Social Empresarial está associada ao envolvimento de todas as partes interessadas para atingir o desenvolvimento sustentável. Isto no mundo das empresas é definido como sustentabilidade dos negócios, que engloba um modelo que tem como base não apenas o aspecto econômico, mas também o social e o ambiental, todos atuando de forma integrada. 


\subsection{Estudos anteriores}

O tema da gestão ambiental vem sendo tratado em estudos bibliométricos, dos quais se destacam discloure, gestão de recursos, contabilidade entre outros temas relacionados à questão ambiental. O trabalho de Gallon, Souza, Rover e Van Bellen (2008), que teve como objetivo traçar um panorama da produção científica em Administração sobre a temática ambiental, resultou em uma análise de 165 artigos sobre a temática ambiental, publicados nos fóruns da área de Administração. Os resultados permitiram perceber que os principais temas abordados foram Gestão dos Recursos Ambientais, Responsabilidade Ambiental, Modelos de Gestão Ambiental, Sustentabilidade Ambiental e Contabilidade/Evidenciação Ambiental. Além disso, o autor destaca que um aspecto positivo nas publicações da área é a identificação de alguma perspectiva de inserção internacional, mas ainda, o uso muito forte de livros, produção consolidada, que não reflete essencialmente o estado da arte da temática.

Em outro caminho, Nascimento, Santos, Salotti e Múrcia (2009) desenvolveram estudo objetivando conhecer as características da pesquisa em discloure social e ambiental, sendo constatado que a área possui um arcabouço teórico e metodológico pluralista com diferentes abordagens para o estudo de seus fenômenos e que diferente de outros países emergentes, não foram identificados trabalhos de pesquisadores brasileiros na amostra estudada.

Com foco em produção gerada na área ambiental, em congressos e periódicos, Silva, Dani, Beuren e Kloeppel (2011) examinaram as características bibliométricas e sociométricas de publicações da área ambiental no Congresso USP de Controladoria e Contabilidade, EnANPAD e em periódicos de Administração e Contabilidade no período de 2000 a 2010, onde concluíram que as publicações da área ambiental sinalizam que o tema continua em evidência e que a configuração estrutural dos relacionamentos dos autores apresenta lacunas, principalmente nos periódicos pesquisados.

Sob o aspecto da gestão, Sehnem, Oliveira, Ferreira e Rosseto (2012) identificaram a evolução do interesse de publicação da administração nas questões da gestão ambiental, estratégia ambiental, desempenho ambiental e avaliação estratégica ambiental (em português, inglês ou espanhol), através da verificação de artigos com estas temáticas em periódicos da área. Destaca-se neste estudo que entre 2000 a 2009 houve uma importante evolução na quantidade de periódicos brasileiros e número de artigos publicados que citaram os termos pesquisados, inclusive por meio de edições especiais sobre a questão ambiental, porém com difusão pouco significativa nas publicações brasileiras.

Por fim, Freitas, Quaresma, Schimitt, Gonçalves e Quintana (2012) analisaram a questão da contabilidade ambiental, procurando limitar-se a verificar a quantidade de artigos publicados sobre o

Revista de Administração e Inovação, São Paulo, v. 11, n.2, p. 07-29, abr./jun. 2014. 
tema, as referências utilizadas, relacionando essas variáveis e sintetizando os temas e contribuições desses trabalhos, onde foi constatado que existem poucas publicações científicas sobre o tema, dentre estas publicações destacam-se a aplicabilidade e evidenciação dos fatores ambientais, e as informações sobre Contabilidade Ambiental ainda não são consideradas como relevantes.

\section{PROCEDIMENTOS METODOLÓGICOS}

A pesquisa classifica-se quanto à natureza como básica, conforme o entendimento de Marconi e Lakatos (2006) e quanto aos objetivos classifica-se como pesquisa exploratória, segundo as definições de Raupp e Beuren (2009). Também se enquadra como pesquisa descritiva, seguindo o conceito elencado por Gil (2002). Quanto aos procedimentos, foram seguidos os preceitos de Martins e Theóphilo (2007). No caso deste estudo os materiais e/ou documentos são as pesquisas anteriormente elaboradas e veiculadas em forma de artigos científicos. Ainda se enquadra como pesquisa bibliométrica, que se fundamenta na descrição e na quantificação. Conforme Kobashi e Santos (2008, p. 109).

A bibliometria é uma metodologia de recenseamento das atividades científicas e correlatas, por meio de análise de dados que apresentem as mesmas particularidades. Por meio dessa metodologia, pode-se, por exemplo, identificar a quantidade de trabalhos sobre um determinado assunto; publicados em uma data precisa; publicados por um autor ou por uma instituição ou difundidos por um periódico científico.

Assim, nesta pesquisa buscou-se comparar e confrontar os elementos representativos das publicações estudadas. Quanto à abordagem do problema, a pesquisa classifica-se como quantitativa, de acordo com o exposto por Oliveira (2002). A coleta de dados é documental, dado que os objetos do estudo são artigos científicos. O tratamento dos dados se realizou por meio de análise de conteúdo. Após a coleta os artigos passaram por uma análise e categorização, conforme os preceitos de Bardin (1977).

O universo de estudo se constitui de pesquisas sobre o tema de gestão ambiental divulgadas em periódicos de administração e contabilidade classificados pela CAPES (2011), nos níveis Webqualis B1 a B4, sendo que a amostra é do tipo não probabilística por julgamento, conforme o entendimento de Colauto e Beuren (2009). A escolha nos níveis B1 a B4 deve-se ao fato que no momento da coleta dos dados, não havia periódicos nacionais da área de administração e contabilidade com nível de Webqualis A1 e A2. A amostra se encontra apresentada no quadro 1, a seguir. 


\begin{tabular}{|c|c|c|}
\hline Periódicos & Sigla & Webqualis \\
\hline Base (UNISINOS) & BASE & B2 \\
\hline Brazilian Business Review & BBR & B2 \\
\hline Cadernos EBAPE.BR (FGV) & EBAPE.BR & B1 \\
\hline Contabilidade Vista \& Revista & CVR & B3 \\
\hline Contabilidade, Gestão e Governança (UNB) & CGG & B4 \\
\hline Pensar Contábil & $\mathrm{PC}$ & B4 \\
\hline RAC Eletrônica & $\mathrm{RAC}$ & B1 \\
\hline RAE Eletrônica & RAE & B1 \\
\hline RAUSP-e (São Paulo) & RAUSP-e & B2 \\
\hline Revista Contabilidade \& Finanças & $\mathrm{RC} \& \mathrm{~F}$ & B1 \\
\hline Revista Contemporânea de Contabilidade (UFSC) & $\mathrm{RCC}$ & B3 \\
\hline Revista de Administração Mackenzie & RAM & B1 \\
\hline Revista de Ciências da Administração (CAD/UFSC) & CAD & B3 \\
\hline Revista de Contabilidade do Mestrado em Ciências Contábeis da UERJ & $\mathrm{RCMCC}$ & B4 \\
\hline Revista de Contabilidade e Organizações & $\mathrm{RCO}$ & B3 \\
\hline Revista de Educação e Pesquisa em Contabilidade & REPEC & B3 \\
\hline Revista de Informação Contábil & RICG & B4 \\
\hline Revista Eletrônica de Administração & READ & $\mathrm{B} 2$ \\
\hline Revista Iberoamericana de Contabilidad de Gestión & RICG & B2 \\
\hline Revista Universo Contábil & RUC & B3 \\
\hline
\end{tabular}
Fonte: CAPES (2011).

Em síntese, a população de estudo se constitui dos vinte periódicos listados no Quadro 1. O período abrangido pelo estudo se refere a todas as edições com artigos disponíveis fulltext, nos portais eletrônicos dos periódicos, objeto de estudo, na primeira semana de setembro de 2011. Na coleta dos dados foram selecionados, primeiramente, pelo título, resumo e palavras-chave o termo "ambient", após foram excluídos os artigos relativos á contabilidade ambiental, restando apenas os de gestão ambiental para análise nesta pesquisa, procurou-se desenvolver um grau de imparcialidade, evitando preferências pessoais, foram utilizados materiais que ainda não haviam recebido um tratamento analítico.

\section{ANÁLISE DE RESULTADOS}

Após a análise e categorização dos artigos por temas tratados, foram excluídos os relativos ao tema de contabilidade ambiental, sendo que os demais, relativos ao tema de gestão ambiental estão apresentados, por periódico e por ano de publicação na Tabela 1, a seguir. 
Tabela 1 - Artigos sobre gestão ambiental

\begin{tabular}{|c|c|c|c|c|c|c|c|c|c|c|c|c|c|}
\hline Periódicos & 2001 & 2002 & 2003 & 2004 & 2005 & 2006 & 2007 & 2008 & 2009 & 2010 & 2011 & Total & $\%$ \\
\hline BBR & & & & & & & & & 1 & & & 1 & $5,6 \%$ \\
\hline CGG & & & & & & & & & & 1 & & 1 & $5,6 \%$ \\
\hline C. EBAPE & & & & & & & & & & & 1 & 1 & $5,6 \%$ \\
\hline PC & & & & & & & 1 & & & 1 & & 2 & $11,0 \%$ \\
\hline RAC & & & & & & & 1 & & & & & 1 & $5,6 \%$ \\
\hline \#RAE & 1 & & 1 & 3 & 1 & & & & 1 & & & 7 & $38,6 \%$ \\
\hline RCC & & & & & & & & & 1 & & & 1 & $5,6 \%$ \\
\hline RCMCC & & & & & & & & & & 1 & & 1 & $5,6 \%$ \\
\hline RIC & & & & & & & & & & 1 & & 1 & $5,6 \%$ \\
\hline RICG & & & & & & & & & & & 1 & 1 & $5,6 \%$ \\
\hline RUC & & & & & & & & & & 1 & & 1 & $5,6 \%$ \\
\hline Total & 1 & $\mathbf{0}$ & 1 & 3 & 1 & $\mathbf{0}$ & 2 & $\mathbf{0}$ & 3 & 5 & 2 & 18 & $100 \%$ \\
\hline
\end{tabular}

Fonte: Dados da pesquisa

Depreende-se pela visualização da Tabela 1, que foram localizados 18 artigos sobre o tema de gestão ambiental. Os periódicos foram revisados desde a sua primeira edição e o assunto somente foi localizado, a partir do ano de 2001, sendo que nos anos de 2004, 2009 e 2010 compreendem o período de maior publicação. Cabe destacar que os anos de 2002, 2006 e 2008 não tiveram nenhuma publicação sobre o assunto. O periódico que se destacou na publicação sobre gestão ambiental foi a Revista de Administração de Empresas da FGV - \#RAE Eletrônica, com 39\% dos artigos publicados do total de dezoito trabalhos.

\subsection{Características dos autores}

Sobre as características autorais são apresentadas informações na Tabela 2 e Quadro 2.

Tabela 2 - Autores por artigo

\begin{tabular}{l|c|c}
\hline \multicolumn{1}{c|}{ Quantidade de autores } & Quantidade de artigos & $\%$ \\
\hline um autor & 4 & 22,22 \\
dois autores & 5 & 27,77 \\
três autores & 3 & 16,67 \\
quatro autores & 3 & 16,67
\end{tabular}




\begin{tabular}{c|c|c} 
cinco autores & 3 & 16,67 \\
\hline Total & $\mathbf{1 8}$ & $\mathbf{1 0 0 , 0 0}$ \\
\hline
\end{tabular}

Fonte: Dados da pesquisa

Observa-se, pela Tabela 2, que não houve muita discrepância entre a quantidade de autores por artigo, sendo que, aproximadamente, $28 \%$ dos artigos analisados foram elaborados por dois autores. Assim, grande maioria dessas pesquisas foram elaboradas em grupos, fato que pode caracterizar grupos de pesquisa com fomento financeiro subsidiando as atividades do grupo. Na pesquisa de Gallon et al. (2007), aproximadamente 44\% dos artigos foram elaborados por um único autor nos periódicos analisados pela pesquisa dos autores, resultado que não se confirmou nesta pesquisa.

\begin{tabular}{|c|c|c|c|c|c|}
\hline Autor & IES & $\begin{array}{c}\text { Estad } \\
\text { o }\end{array}$ & Autor & IES & Local \\
\hline Abreu, M. C. S. & UFC & $\mathrm{CE}$ & Alberton, A. & NI & NI \\
\hline Baptista, E. C. S. & FUCAPE & ES & Cezar, J. F. & $\begin{array}{l}\text { Fundação Educacional e Cultural } \\
\text { São José }\end{array}$ & RJ \\
\hline Bianchi, M. & UFRGS & RS & Colpo, K. D. & $\begin{array}{c}\text { Universidade Estadual } \\
\text { Paulista Júlio de Mesquita Filho }\end{array}$ & SP \\
\hline Carvalho, S. & FGV & $\mathrm{SP}$ & Costa Júnior, N. C. A. & $\mathrm{NI}$ & $\mathrm{NI}$ \\
\hline Corazza, R. I. & FACAMP & SP & Franco, J. M. & $\begin{array}{l}\text { Universidade Regional Integrada } \\
\text { do Alto Uruguai e das Missões }\end{array}$ & RS \\
\hline Corrêa, S. R. S. & UFRJ & RJ & Gelatti, R. & $\begin{array}{l}\text { Instituto Cenecista de Ensino } \\
\text { Superior de Santo Ângelo - } \\
\text { IESA }\end{array}$ & RS \\
\hline Correia, S. L. A. & UESC & BA & Ponchirolli, O. & FAE & PR \\
\hline Crubellate, J. M. & UEM & $\mathrm{PR}$ & Rados, G. J. V. & UFSC & $\mathrm{SC}$ \\
\hline Estival, K. G. S. & UFRJ & RJ & Richartz, F. & UFSC & $\mathrm{SC}$ \\
\hline Fernandes, V. & FAE & PR & Rossetto, A. M. & UNIVALI & $\mathrm{SC}$ \\
\hline Freitas, C. L. & UFSC & $\mathrm{SC}$ & Rossetto, C. R. & UNIVALI & $\mathrm{SC}$ \\
\hline $\begin{array}{l}\text { Gonçalves-Dias, S. L. } \\
\text { F. }\end{array}$ & PUC & SP & Santos, A. & USP & SP \\
\hline Jesus, F. N. & UESC & BA & Silva Júnior, A. & FUCAPE & ES \\
\hline Junqueira, M. S. D. & FGV & $\mathrm{SP}$ & Silva, H. M. R. & FGV & SP \\
\hline Lavarda, R. A. B. & FURB & $\mathrm{SC}$ & Soares, G. M. P. & UFPR & PR \\
\hline Lelis, M. T. C. & UFRGS & RS & Sudati, L. U. & $\begin{array}{c}\text { Universidade Regional Integrada } \\
\text { do Alto Uruguai e das Missões }\end{array}$ & RS \\
\hline Lobato, C. E. & UFRGS & RS & Teodósio, A. S. S, & PUC & MG \\
\hline Machado, M. A. V. & UFPB & $\mathrm{PB}$ & Autor & IES & País \\
\hline Machado, M. R. & UFPB & PB & Eugênio, T. & $\begin{array}{c}\text { Escola Superior de Tecnologia e } \\
\text { Gestão de Leiria }\end{array}$ & Portugal \\
\hline Melo, S. E. & UESC & $\mathrm{BA}$ & Freire, R. P. A. S. & Universidade de Granada & Espanha \\
\hline Nossa, S. N. & FUCAPE & ES & Pérez, M. V. L. & Universidade de Granada & Espanha \\
\hline Nossa, V. & FUCAPE & ES & Silva, F. C. A. & Universidade de Granada & Espanha \\
\hline Pfitscher, E. D. & UFSC & $\mathrm{SC}$ & Figueiredo Júnior, H. S. & Consultor de empresas & USA \\
\hline
\end{tabular}


O Quadro 2 apresenta os autores dos artigos analisados, bem como suas Instituições de Ensino Superior (IES) vinculadas e o local das mesmas. Ao total foram 45 autores distintos, sendo que apenas a autora SILVA, F. C. A. possui dois artigos publicados na amostra estudada, os demais autores possuem apenas um artigo cada um.

A Fucape Business School e a Universidade Federal de Santa Catarina se destacaram das demais, sendo citadas como vínculo institucional 4 vezes cada uma. Em segundo lugar, com 3 vezes cada uma ficaram a Fundação Getúlio Vargas, a Universidade Estadual de Santa Cruz, a Universidade Federal do Rio Grande do Sul e a Universidade de Granada. Os estados, respectivamente são: Fucape - ES, UFSC - SC, FGV - SP, UESC - BA, UG - Espanha.

\subsection{Características dos temas pesquisados}

Os temas pesquisados nos artigos analisados estão apresentados na Tabela 3 e no quadro 3, a seguir.

Tabela 3 - Temas pesquisados

\begin{tabular}{|c|c|c|c|c|c|c|c|c|c|c|}
\hline Tema & 2001 & 2003 & 2004 & 2005 & 2007 & 2009 & 2010 & 2011 & Total & $\%$ \\
\hline Benefício ambiental & 1 & & & & & & & & 1 & 5,6 \\
\hline Controle social & & & 1 & & & & & & 1 & 5,6 \\
\hline Desempenho ambiental/social & & 1 & & & & 1 & & 1 & 3 & 16,6 \\
\hline Determinismo ambiental & & & & 1 & & & & & 1 & 5,6 \\
\hline Educação superior & & & & & & 1 & & & 1 & 5,6 \\
\hline Informação ambiental & & & & & 1 & & 2 & & 3 & 16,6 \\
\hline Investimento social e ambiental & & & & & & & 2 & & 2 & 11,0 \\
\hline Racionalidade ambiental & & & & & & & & 1 & 1 & 5,6 \\
\hline Responsabilidade social & & & 1 & & & & & & 1 & 5,6 \\
\hline Sistemas de gestão ambiental & & & 1 & & 1 & & 1 & & 3 & 16,6 \\
\hline Sustentabilidade ambiental & & & & & & 1 & & & 1 & 5,6 \\
\hline Total & 1 & 1 & 3 & 1 & 2 & 3 & 5 & 2 & 18 & 100,0 \\
\hline
\end{tabular}

Conforme se observa na Tabela 3, os artigos foram separados por subáreas temáticas. As mesmas foram elencadas a partir do foco central da revisão de literatura de cada trabalho analisado. Percebe-se que os estudos se concentram em desempenho ambiental e social, informação ambiental, sistemas de gestão ambiental e, por fim, investimento social e ambiental. Destaca-se que todos os trabalhos estão atrelados a gestão e sustentabilidade ambiental. O estudo de Gallon et al. (2007) 
realizado sobre a produção de 2000 a 2006, também encontrou esses assuntos como sendo os mais procurados.

\begin{tabular}{|r|l|r|l|r|l|}
\hline 1 & Isomorfismo & 1 & Educação superior & 1 & Mudança organizacional \\
\hline 1 & Adicionalidade & 1 & Eficiência & 1 & NBR ISO 14001 \\
\hline 1 & Adaptação estratégica & 1 & Empresas & 1 & Organizações industriais \\
\hline 1 & Álcool combustível & 1 & Energia renovável & 1 & Participação \\
\hline 1 & Análise de Sustentabilidade Ambiental & 1 & Estratégia & 1 & Performance ambiental \\
\hline 1 & Balanced Scorecard & 1 & Estratégias pedagógicas & 1 & Perspectiva institucional \\
\hline 1 & Burocracia & 1 & Estrutura da indústria & 1 & Protocolo de Kyoto \\
\hline 1 & Capital intelectual & 1 & Estrutura organizacional & 1 & Questões de investigação \\
\hline 1 & Capitalismo & 1 & Estudo de caso & 1 & Racionalidade ambiental \\
\hline 1 & Comportamento ambiental & 1 & Formação de administradores & 1 & Racionalidade comunicativa \\
\hline 1 & Contradições & 1 & Fotossíntese & 1 & Racionalidade substantiva \\
\hline 1 & Controle social & 1 & Gerenciamento de resíduos & 1 & Racionalização \\
\hline 1 & Dados em Painel & 5 & Gestão ambiental & 1 & Responsabilidade ambiental \\
\hline 1 & Decisão & 1 & Gestão do conhecimento & 3 & $\begin{array}{l}\text { Responsabilidade Social } \\
\text { Corporativa }\end{array}$ \\
\hline 1 & dependência de recursos & 2 & Gestão empresarial & 1 & Retorno anormal \\
\hline 1 & Desempenho financeiro & 1 & Indicadores ambientais & 1 & Setor econômico \\
\hline 1 & Determinismo ambiental & 1 & Indústria de Bebidas & 1 & Sistemas de gestão ambiental \\
\hline 1 & Discursos & 1 & Informações de Sustentabilidade & 2 & Stakeholders \\
\hline 1 & Divulgação social e ambiental & 2 & $\begin{array}{l}\text { Investimentos sociais e } \\
\text { ambientais }\end{array}$ & 2 & Teoria da Legitimação \\
\hline 1 & 2 & Meio ambiente & 1 & Teoria organizacional \\
\hline 1 & Educação ambiental & 1 & Motivação dos gestores & & \\
\hline & & Fonte: Dados da pesquisa & & \\
\hline
\end{tabular}

O Quadro 3 complementa a análise apresentada na Tabela 3, sendo que, foram utilizadas 73 palavras-chave nos artigos analisados, com uma média aproximada de 4 palavras-chave por trabalho. Conforme Martins e Theóphilo (2007) as palavras-chave devem estar atreladas ao problema e objetivos da pesquisa, bem como o título, revisão de literatura e tema tratados. Destaca-se que as palavras-chave devem facilitar a localização do trabalho publicado. Desta forma, as informações dos autores devem estar amparadas nesse pré-requisito. 


\subsection{Características metodológicas utilizadas nas pesquisas}

Neste estudo, foram observadas algumas características metodológicas utilizadas nas pesquisas divulgadas pelos artigos científicos analisados. As mesmas apresentam-se na Tabela 4, a seguir.

Tabela 4 - Tipos de pesquisas e instrumento de coleta de dados

\begin{tabular}{|c|c|c|c|}
\hline Grupos & Subgrupos & Quantidade & $\%$ \\
\hline $\begin{array}{c}\text { Classificação da pesquisa quanto aos } \\
\text { objetivos }\end{array}$ & $\begin{array}{l}\text { Exploratória } \\
\text { Descritiva } \\
\text { Explicativa } \\
\text { Subtotal }\end{array}$ & $\begin{array}{c}6 \\
5 \\
7 \\
\mathbf{1 8}\end{array}$ & $\begin{array}{r}33,3 \\
27,8 \\
38,9 \\
\mathbf{1 0 0 , 0}\end{array}$ \\
\hline $\begin{array}{c}\text { Classificação da pesquisa quanto à } \\
\text { abordagem do Problema de pesquisa }\end{array}$ & $\begin{array}{l}\text { Qualitativa } \\
\text { Quantitativa } \\
\text { Quali-quanti } \\
\text { Subtotal }\end{array}$ & $\begin{array}{c}12 \\
5 \\
1 \\
\mathbf{1 8}\end{array}$ & $\begin{array}{c}66,7 \\
27,8 \\
5,5 \\
\mathbf{1 0 0 , 0}\end{array}$ \\
\hline $\begin{array}{c}\text { Classificação da pesquisa quanto aos } \\
\text { procedimentos de realização da pesquisa }\end{array}$ & $\begin{array}{l}\text { bibliográfica } \\
\text { documental } \\
\text { survey } \\
\text { estudo de caso } \\
\text { Subtotal }\end{array}$ & $\begin{array}{c}9 \\
5 \\
2 \\
2 \\
18\end{array}$ & $\begin{array}{r}50,0 \\
27,8 \\
11,1 \\
11,1 \\
\mathbf{1 0 0 , 0}\end{array}$ \\
\hline $\begin{array}{l}\text { Instrumentos de coleta de dados utilizados } \\
\text { nas pesquisas }\end{array}$ & $\begin{array}{l}\text { documentos } \\
\text { questionário } \\
\text { banco de dados } \\
\text { Subtotal }\end{array}$ & $\begin{array}{c}13 \\
3 \\
2 \\
18\end{array}$ & $\begin{array}{r}72,2 \\
16,7 \\
11,1 \\
\mathbf{1 0 0 , 0}\end{array}$ \\
\hline
\end{tabular}

Fonte: Dados da pesquisa

Utilizou-se como base para a análise da classificação das pesquisas e dos instrumentos de coleta de dados utilizados a literatura de metodologia aplicada à contabilidade e as ciências sociais, tais como: Martins (2002), Silva (2003), Marconi e Lakatos (2006), Martins e Theóphilo (2007) e Raupp e Beuren (2009).

Conforme o apresentado na Tabela 4 e as recomendações da literatura consultada, quanto aos objetivos a tipologia de pesquisa mais utilizada foi a explicativa com 38,9\% do total, esse fato se deve ao enlace das revisões de literatura utilizadas nas pesquisas bibliográficas. $\mathrm{O}$ estudo de Gallon et al. (2007) apresentou o estudo de caso como sendo o mais utilizado no período do estudo, fato que não se confirmou nesta pesquisa. 
Nesse contexto, quanto à abordagem do problema de pesquisa a tipologia mais utilizada foi a pesquisa qualitativa com $66,7 \%$ e quanto aos procedimentos de pesquisa obteve destaque a pesquisa bibliográfica com 50\% dos trabalhos analisados. Desta forma, não foram utilizadas pesquisas etnográficas, nem mesmo experimentais. Semelhante ao resultado da pesquisa de Gallon et al. (2007) que encontrou a tipologia qualitativa para a subárea de gestão ambiental com $63,15 \%$ do total da amostra.

Quanto aos instrumentos de coleta de dados, apresentados na Tabela 4, o destaque foi para a pesquisa em documentos com $72,2 \%$, haja vista o relacionamento com a pesquisa bibliográfica citada nos procedimentos, que é realizada em documentos com fontes primárias ou secundárias. Com base na literatura consultada, destaca-se que não foram utilizados dentre outros, os seguintes instrumentos: observação, entrevista, focus group e análise de discurso.

\subsection{Características das referências utilizadas nas pesquisas}

As características das referências utilizadas estão apresentadas na Tabela 5 e Quadro 4 e 5, a seguir.

Tabela 5 - Tipos de pesquisas e instrumento de coleta de dados

\begin{tabular}{|c|c|c|}
\hline Referências & Quantidade & $\%$ \\
\hline Artigos de congressos & 55 & 9,3 \\
\hline Artigos de periódicos & 220 & 37,0 \\
\hline Livros & 224 & 37,7 \\
\hline Teses & 12 & 2,0 \\
\hline Dissertações & 7 & 1,2 \\
\hline Normas & 8 & 1,3 \\
\hline Internet & 37 & 6,2 \\
\hline Outros & 31 & 5,3 \\
\hline Total & 594 & 100,0 \\
\hline Nacional & 275 & 46,3 \\
\hline Internacional & 319 & 53,7 \\
\hline Total & 594 & 100,0 \\
\hline
\end{tabular}

Fonte: Dados da pesquisa

Conforme a Tabela 5, das 594 referências utilizadas nos 18 artigos analisados, o que reflete uma média de 33 referências por artigo. Salienta-se que os artigos de periódicos e os livros somados representam a maioria das tipologias utilizadas, ou seja, 74,7\%. Ainda das 594 referências utilizadas, 
53,7\% são internacionais. Acrescenta-se a informação que dentre as línguas estrangeiras utilizadas, o inglês, o espanhol e o francês, a primeira é que obteve a maioria das 319 referências internacionais.

Esse resultado demonstra que o assunto gestão ambiental possui relevante literatura estrangeira e, deste modo, os pesquisadores que desejarem buscar esta temática devem estar preparados para esse contato.

\begin{tabular}{|c|l|}
\hline Quantidade & \multicolumn{1}{|c|}{ Referência } \\
\hline 3 & $\begin{array}{l}\text { O'Donovan, G. (2002). Environmental disclosures in the annual report: Extending tha } \\
\text { applicability and predictive power of legitimacy theory. Accounting, Auditing \& } \\
\text { Accountability Journal, 15(3), 344-371. }\end{array}$ \\
\hline 3 & $\begin{array}{l}\text { Porter, M. E., \& Linde, C. Van Der (1995a). Green and competitive. Harvard Business } \\
\text { Review, 73(5), 120-134. }\end{array}$ \\
\hline 2 & $\begin{array}{l}\text { Gray, R., Kouhy, R. \& Lavers, S. (1995). Corporate social and environmental reporting: a } \\
\text { review of the literature and a longitudinal study of UK disclosure. Accounting, Auditing \& } \\
\text { Accountability Journal, 8(2), 47-81. }\end{array}$ \\
\hline 2 & $\begin{array}{l}\text { IBASE - Instituto Brasileiro de Análises Sociais e Econômicas. Dados. Disponível em: } \\
\text { <http://www.ibase.org.br/>. Acesso em: 20 jul. 2006. }\end{array}$ \\
\hline 2 & $\begin{array}{l}\text { Tinoco, J. E. P.; Kraemer, M. E. P. (2004). Contabilidade e gestão ambiental. São Paulo: } \\
\text { Atlas. }\end{array}$ \\
\hline
\end{tabular}

Quadro 4 - Obras mais prolíferas sobre a temática ambiental

Fonte: Dados da pesquisa

Quanto às obras mais utilizadas, das 594 utilizadas ao total apenas 5 obtiveram destaque, conforme elencadas no Quadro 4. Muitas referências eram relativas a métodos de pesquisa, a relações de trabalho, ao racionalismo, a estrutura organizacional e contábil, dentre outros assuntos, deste modo foram selecionados apenas as obras relativas à temática ambiental, destaca-se que 3 dessas principais estão no idioma inglês.

\begin{tabular}{|c|l|}
\hline Quantidade & Autor \\
\hline 4 & Gray, R. \\
\hline 4 & Scott, W. R. \\
\hline 4 & Tinoco, J. E. P. \\
\hline 3 & Abreu, M. C. \\
\hline 3 & AKATU - INSTITUTO \\
\hline 3 & Barbieri, J. C. \\
\hline 3 & Carroll, A. B. \\
\hline 3 & Donaire, D. \\
\hline 3 & Dowling, J. \\
\hline 3 & Leff, E. \\
\hline 3 & Macedo, I. C. \\
\hline 3 & Machado da Silva, C. \\
\hline
\end{tabular}




\begin{tabular}{|l|l|}
3 & O'Donovan, G. \\
\hline 3 & Porter, M. E. \\
\hline
\end{tabular}

Quadro 5 - Autores mais prolíferos sobre a temática ambiental

Fonte: Dados da pesquisa

O Quadro 5 apresenta a listagem dos autores mais referenciados nos artigos analisados. Nota-se que os três primeiros autores foram referenciados 4 vezes cada um, os demais 3 vezes cada um. Salienta-se que AKATU não é um autor e sim uma base de dados de informações ambientais. Os autores Donaire e Porter também são elencados na pesquisa de Gallon et al. (2007).

\section{CONSIDERAÇÕES FINAIS}

Após a análise dos artigos divulgados nos vinte periódicos científicos selecionados na amostra do estudo, apenas dezoito publicaram artigos inerentes a temática de gestão ambiental. Alguns destaques são resgatados a fim de responder o objetivo central da pesquisa, que foi identificar as características da produção científica em gestão ambiental, em periódicos classificados nos níveis Webqualis B1 a B4 pela CAPES (2011), da área de administração e contabilidade.

O resultado da análise dos 18 artigos localizados sobre a temática indicou que o período de divulgação destes foi de 2001 a 2011, sendo que a maior quantidade de publicações foi nos anos de 2004, 2009 e 2010.

Quanto às características de autoria a pesquisa demonstrou que a maioria dos artigos foi elaborada por grupos de 5 autores, ao total foram 45 autores distintos e a Fucape Business School e a Universidade Federal de Santa Catarina se destacaram das demais nos vínculos institucionais dos autores.

Com relação aos temas, ou subáreas pesquisadas, conjuntamente com a gestão ambiental, destacaram-se: o desempenho ambiental e social, a informação ambiental, os sistemas de gestão ambiental e o investimento social e ambiental. Ainda a palavra-chave que mais se destacou foi a de gestão ambiental.

Sobre as características metodológicas salientaram-se o uso da pesquisa explicativa, bibliográfica e qualitativa com a coleta de dados por meio de documentos.

Das 594 referências utilizadas nos 18 artigos analisados foram em grande parte de língua estrangeira, com citações de artigos de periódicos e livros em sua maioria. Poucas obras puderam ser identificadas nesse contingente de referências sobre a temática ambiental especificamente. Ainda, os 
autores Donaire e Porter, elencados nesta pesquisa, como sendo alguns dos mais prolíferos, também foram citados em estudos anteriores.

Conclui-se, que a quantidade de estudos em Gestão Ambiental, nos periódicos pesquisados, é bastante limitada, focando a pesquisa bibliográfica, por meio documental, que não exploram a realidade da Gestão Ambiental com a devida profundidade, detendo-se, apenas na evolução do desempenho ambiental e na informação gerada sobre as questões ambientais, sem destacar os reflexos que um processo de gestão ambiental pode trazer para a gestão das entidades e para a sociedade em geral.

As limitações do estudo estão atreladas as interpretações dos pesquisadores, pois a análise de conteúdo não foi executada mecanicamente e sim manualmente. Sugestões de estudos futuros se destinam a investigar as causas de tão incipiente publicação numa área do conhecimento tão prolífera em outras ciências.

\section{REFERÊNCIAS}

Alberton, A., \& Costa, N. C. A. (2007, maio/agosto). Meio Ambiente e Desempenho EconômicoFinanceiro: Benefícios dos Sistemas de Gestão Ambiental (SGAs) e o Impacto da ISO 14001 nas Empresas Brasileiras. RAC-Eletrônica, 1 (2), 153-171.

Almeida, N. C. V. (2010). Sistema de Gestão Ambiental: um estudo dos terminais do Porto de Santos. Dissertação de Mestrado, Fundação Getúlio Vargas, São Paulo, SP, Brasil.

Barbieri, J. C. (2007). Gestão Ambiental Empresarial: Conceitos, modelos e instrumentos (2a ed.). São Paulo: Saraiva.

Barbosa, D. S., Machado, D. G., \& Quintana, A. C. (2011, maio/agosto). Análise da Produção Científica sobre os fluxos de caixa e a demonstração dos fluxos de caixa: um estudo da Revista de Contabilidade e Finanças da Universidade de São Paulo, no período de 1989 a 2009. Revista Enfoque: Reflexão Contábil, 30(2), 52-66.

Bardin, L. (1977). Análise de conteúdo. Lisboa: Edições 70. 
Beuren, I. M., Schlindwein, A. C., \& Pascal, D. L. (2007, setembro/dezembro). Abordagem de controladoria em trabalhos publicados no EnANPAD e no Congresso USP de Controladoria e Contabilidade de 2001 a 2006. Revista de Contabilidade \& Finanças, 18(45), 22-37.

Bianchi, M., Gelatti, R., Lelis, M. T. C., \& Lobato, C. E. (2010, outubro/novembro). A (falta de) relação entre investimentos em meio ambiente e crescimento nas vendas: uma análise com dados em painel. RIC - Revista de Informação Contábil, 4(4), 65-82.

Cintra, Y. C. (2011). A integração da sustentabilidade às práticas de controle gerencial da empresas no Brasil. Tese de Doutorado, Universidade de São Paulo, São Paulo, SP, Brasil.

Colauto, R. D., \& Beuren, I. M. (2009). Coleta, Análise e Interpretação dos Dados. In: BEUREN; Ilse Maria (coord.). Como Elaborar Trabalhos Monográficos em Contabilidade (3a ed.). São Paulo: Atlas.

Coordenação de Aperfeiçoamento de Pessoal de Nível Superior (2011). Periódicos cadastrados. Recuperado em 07 de agosto, 2011, de http://www.periodicos.capes.gov.br/portugues/index.jsp

Diehl, C. A., \& Souza, M. A. (2008, outubro/dezembro). Publicações sobre o Custeio Baseado em Atividades (ABC) em Congressos Brasileiros de Custos no Período de 1997 a 2006. Revista Contabilidade Vista e Revista, 19(4), 39-57.

Espejo, M. M. S. B, Cruz, A. P. C., Lourenço, R. L., \& Antonovz, T. (2008, setembro). Estado da Arte da Pesquisa Contábil: Um estudo bibliométrico de periódicos nacional e internacionalmente veiculados entre 2003 e 2007. Anais do Encontro Nacional da Associação Nacional de Pós-Graduação em Administração, Rio de Janeiro, Brasil, 32.

Ferreira, A. C. S. (2009). Contabilidade Ambiental: uma informação para o desenvolvimento sustentável - inclui Certificados de Carbono (2a ed.). São Paulo: Atlas.

Freitas, D. P. S., Quaresma, J. C. C., Schimitt, S. R. Z., Gonçalves, T. L., \& Quintana, A. C. (2012, janeiro/junho). Contabilidade Ambiental: um estudo bibliométrico em revistas científicas brasileiras. Revista Ambiente Contábil, v. 4(1), 72-88. 
Gallon, A. V., Souza, F. C., Rover, S., \& Van Bellen, H. M. (2007). Produção científica e perspectivas teóricas da área ambiental: um levantamento a partir de artigos publicados em congressos e periódicos nacionais da área de contabilidade e administração. Anais do Congresso USP de Controladoria $e$ Contabilidade, São Paulo, Brasil, 7.

Gallon, A. V., Souza, F. C., Rover, S., \& Van Bellen, H. M. (2008, janeiro/abril). Um estudo longitudinal da produção científica em administração direcionada à temática ambiental. Alcance, 15(1), 81-101.

Gil, A. C. (2002). Técnicas de pesquisa em economia e elaboração de monografias. São Paulo: Atlas.

Kitzmann, D. I. S. (2009). Ambientalização sistêmica na gestão e na educação ambiental: um estudo de caso com o ensino profissional marítimo - EPM. Tese de Doutorado, Universidade Federal do Rio Grande - FURG, Rio Grande, RS, Brasil.

Kobashi, N. Y., \& Santos, R. N. M.. (2008, janeiro/junho). Arqueologia do Trabalho Imaterial: uma aplicação bibliométrica à análise de dissertações e teses. Encontros Bibli: Revista Eletrônica de Biblioteconomia e Ciência da Informação, especial, 106-115.

Kraemer, M. E. P. (2002). Contabilidade Ambiental: Relatório para um Futuro Sustentável, Responsável e Transparente. Recuperado em 14 de dezembro, 2010, de http://www.universoambiental.com.br/Contabilidade/Contabilidade_FuturoSust.htm

Lacombe, F. J. M., \& Heilborn, G. L. J. (2008). Administração: princípios e tendências (2a ed.). São Paulo: Saraiva.

Marconi, M. A., \& Lakatos, E. M. (2006). Fundamentos de Metodologia Científica (6a ed.). São Paulo: Atlas.

Martins, G. A. (2002). Manual para elaboração de monografias e dissertações (3a ed.). São Paulo: Atlas. 
Martins, G. A., \& Theóphilo, C. R. (2007). Metodologia da investigação científica para ciências sociais aplicadas. São Paulo: Atlas.

Moraes, C. S. B. (2006). Planejamento e gestão ambiental: uma proposta metodológica. Tese de Doutorado, Universidade de São Paulo, São Paulo, SP, Brasil.

Nascimento, A. R., Santos, A., Salotti, B., \& Múrcia, F. D-R. (2009, janeiro/março). Disclosure Social e Ambiental: Análise das Pesquisas Científicas Veiculadas em Periódicos de Língua Inglesa. Revista Contabilidade Vista \& Revista, 20(1), 15-40.

Nascimento, L. F., Lemos, A. D. C., \& Mello, M. C. A. (2008). Gestão socioambiental estratégica. Porto Alegre: Bookman.

Nossa, V. (2002). Disclosure Ambiental: uma análise do conteúdo dos relatórios ambientais de empresas do setor de papel e celulose em nível internacional. Tese de Doutorado, Universidade de São Paulo, São Paulo, SP, Brasil.

Oliveira, S. M. (2009). A gestão sócio-ambiental e inovação no setor sucroalcooleiro: um estudo de caso na pioneiros Bionergia S/A. Dissertação de Mestrado, Universidade Federal do Rio Grande do Sul - UFRGS, Porto Alegre, RS, Brasil.

Oliveira, S. L. (2002). Tratado de metodologia científica. São Paulo: Pioneira Thonson Learning.

Paiva, P. R. (2009). Contabilidade ambiental: evidenciação dos gastos ambientais com transparência e focada na prevenção. São Paulo: Atlas.

Philippi, A. Jr. (2002). O impacto da capacitação em gestão ambiental. Tese de Livre-docência, Universidade de São Paulo, São Paulo, SP, Brasil.

Portal Ecodebate: Cidadania e Meio Ambiente (2010). Desastre ambiental no Golfo do México: Vazamento de petróleo na Flórida pode custar 195 mil empregos e quase US\$ 11 bilhões. Rio de Janeiro, Recuperado em 30 de agosto, 2010, de http:/www.ecodebate.com.br/2010/06/11/desastre- 
ambiental-no-golfo-do-mexico-vazamento-de-petroleo-na-florida-pode-custar-195-mil-empregos-equase-us-11-bilhoes/.

Raupp, F. M., \& Beuren, I. M. (2009). Metodologia da Pesquisa Aplicável às Ciências Sociais. In: Beuren, I. M. (coord.). Como Elaborar Trabalhos Monográficos em Contabilidade (3a ed.). São Paulo: Atlas.

Rosseti, E. K. (2008). Gestão Ambiental: Eco eficiência a caminho da sustentabilidade: O caso do segmento moveleiro da serra gaúcha. Dissertação de Mestrado, Universidade de Caxias do Sul, Caxias do Sul, RS, Brasil.

Sehnem, S., Oliveira, M. A. C., Ferreira, E., \& Rossetto, A. M. (2012, maio/agosto). Gestão e Estratégia Ambiental: um estudo bibliométrico sobre o interesse do tema nos periódicos acadêmicos brasileiros. REAd, 72(2), 468-493.

Silva, A. C. R. (2003). Metodologia da pesquisa aplicada a contabilidade: orientações de estudos, projetos, artigos, relatórios, monografias, dissertações, teses. São Paulo: Atlas.

Silva, M. Z., Dani, A. C., Beuren, I. M., \& Kloeppel, N. R. (2011). Características Bibliométricas e Sociométricas de Publicações da área ambiental em Congressos e Periódicos Nacionais. Anais do Encontro Nacional sobre Gestão Empresarial e Meio Ambiente, São Paulo, Brasil, 13.

Sirvinskas, L. P. (2010). Manual de direito ambiental (8a ed.). São Paulo: Saraiva.

Theóphilo, C. R. (2004). Pesquisa em contabilidade no Brasil: uma análise crítico-epistemológica. Tese de Doutorado, Universidade de São Paulo, São Paulo, SP, Brasil.

Vellani, C. L. (2007). A ciência Contábil e a eco-eficiência dos negócios. Dissertação de Mestrado, Universidade de São Paulo, Ribeirão Preto, SP, Brasil. 


\title{
ENVIRONMENTAL MANAGEMENT: SCIENTIFIC PRODUCTION PUBLISHED IN NATIONAL JOURNALS QUALIS B1 TO B4 - CAPES
}

\begin{abstract}
Concern for the environment dates from XIX century, but only in 1972, with the World Conference on Environment held in Stockholm, the country and society as a whole began, more effectively, to worry about the issue global environmental. In this context there is the following research question: how environmental management is being explored in the literature of permanent Administration and Accounting? The overall objective of this work is to identify how environmental management is being explored in ongoing scientific literature, Administration and Accounting in journals classified in levels B1 to B4 Webqualis by CAPES. The survey classified as basic and exploratory. Also characterized as descriptive and bibliometric survey. The approach to the problem the research is classified as quantitative data collection and documentation. The results were to conclude that the number of studies in Environmental Management in the journals surveyed, is quite limited, focusing on literature search through documentary, which do not exploit the reality of Environmental Management with proper depth, stopping, only in the development of environmental performance and generated information on environmental issues, without highlighting the reflections that a process of environmental management can bring to the management of organizations and to society in general.
\end{abstract}

Keywords: Environmental Management; Bibliometric Research; Scientific Production.

Data do recebimento do artigo: 06/06/2013

Data do aceite de publicação: 15/01/2014

Revista de Administração e Inovação, São Paulo, v. 11, n.2, p. 07-29, abr./jun. 2014. 